\title{
Influence of Ionic Strength on the Viscosities and Water Loss of Bentonite Suspensions Containing Polymers
}

\author{
Luciana Viana Amorim*, Maria Ingrid Rocha Barbosa, Hélio de Lucena Lira, Heber Carlos Ferreira \\ Universidade Federal de Campina Grande - UFCG, \\ Programa de Recursos Humanos - PRH-25 \\ Av. Aprígio Veloso, 882, Bodocongó, Bloco CB - Térreo, \\ 58109-970 Campina Grande - Paraíba, Brazil
}

Receiced: May 12, 2006; Revised: December 20, 2006

\begin{abstract}
A study was made of the influence of ionic strength (S) on the apparent (AV) and plastic (PV) viscosities and water loss (WL) of sodium bentonite suspension with polymers. Na-bentonite was dispersed in water $(4.86 \% \mathrm{w} / \mathrm{w})$ of different ionic strengths $(\mathrm{S}=0.0,0.015,0.030$ and $0.045 \mathrm{M})$ followed by the addition of polymer. Three polymer samples were studied, i.e., low viscosity carboxymethyl cellulose (CMC BV), polyanionic cellulose (PAC), and partially hydrolyzed polyacrylamide (HPAM). The results indicated that the presence of salts and increased salinity greatly influence the apparent and plastic viscosities and water loss of bentonite suspensions with polymer.
\end{abstract}

Keywords: bentonite, rheology, polymer, ionic strength

\section{Introduction}

The rheological properties of clay-water systems are important in several technological applications and are dependent mainly on clay particle interactions. Depending on the type of interaction among clay particles, flocculated and deflocculated structures are produced and can be modified by additives such as electrolytes, polymers and surfactants ${ }^{1}$

In recent years, several works have focused on evaluating the effect of ionic and nonionic polymers ${ }^{1-3}$, cationic ${ }^{4}$ and anionic ${ }^{5,6}$ surfactants and electrolytes ${ }^{7}$ on the rheology and stabilization of the bentonite-water system based on measurements of its plastic viscosity, yield strength and zeta potential.

When water-soluble polymers are added to bentonite suspensions, they disperse in the liquid phase (water), their functional groups dissociate and the polymeric chain assumes a straight configuration. The chains are adsorbed on clay particle surfaces according to their ionic nature ${ }^{8}$.

The deflocculation of the system by adsorption of polyelectrolyte on the clay surface is explained by steric and electrosteric stabilization mechanisms ${ }^{9}$. Also, flocculation of the systems can be achieved and are explained by i) the formation of bridges, i.e., lateral interactions between hydrophobic groups of polymers that approach the clay particles ${ }^{10}$; ii) segments of the same polymeric chains that are adsorbed on different clay particles linked to each other and interacting by attraction; and iii) the encapsulation phenomenon, i.e., formation of large flocs of particles or clay particle agglomerates ${ }^{11}$.

According to Hughes et al. ${ }^{3}$, polyelectrolytes such as carboxymethyl cellulose (CMC) and polyanionic cellulose (PAC) are highly dependent on salinity through the ionic strength (S) of solutions. The intrinsic viscosity of ionic polymers declines sharply with increasing $\mathrm{S}$.

The ionic strength $(\mathrm{S})$ of a solution is defined according to Equation 1:

$$
S=\frac{1}{2} \sum C_{i} Q_{i}^{2}
$$

where $C_{i}$ is the concentration of $i$ ions and $Q_{i}$ is the charge of $i$ ions.
This work involved a study of the influence of ionic strength on the plastic and apparent viscosities and the water loss of sodium bentonite suspensions treated with polymers.

\section{Experimental Study}

A bentonite sample was collected in the state of Paraíba in northeastern Brazil. This sample was composed mainly of minerals of the smectite clay group and contained a minor amount of quartz, as indicated by $x$ ray diffraction (XRD), differential thermal analysis (DTA), infrared (IR) and transmission electron microscopy (TEM) analyses. The chemical analysis showed the following results (wt. (\%)): $54.97 \mathrm{SiO}_{2}, 16.82 \mathrm{Al}_{2} \mathrm{O}_{3}, 6.83 \mathrm{Fe}_{2} \mathrm{O}_{3}$, trace $\mathrm{CaO}$, trace $\mathrm{MgO}, 0.38 \mathrm{Na}_{2} \mathrm{O}$, and $0.15 \mathrm{~K}_{2} \mathrm{O}$. The ignition loss was $18.42 \%$ and insoluble residue was $1.79 \%^{2}$.

The cation exchange capacity (CEC) was measured by the methylene blue adsorption method. The CEC was $76 \mathrm{meq} / 100 \mathrm{~g}$ of clay. The specific area was measured by the methylene blue adsorption and BET methods, and the values obtained were $593 \mathrm{~m}^{2} / \mathrm{g}$ and $50.1 \mathrm{~m}^{2} / \mathrm{g}$, respectively. This bentonite clay is usually employed in drilling fluids and as a pet litter adsorbent ${ }^{8}$.

The bentonite sample was changed to Na-bentonite by treating it with $7.85 \% \mathrm{w} / \mathrm{w}$ of $\mathrm{Na}_{2} \mathrm{CO}_{3}$ and curing it in a chamber at a relative humidity of $100 \%$ for 5 days.

Three polymers were involved in this study: 1) a low-viscosity carboxymethyl cellulose (CMC BV), with an 0.85 degree of substitution (DS), 70,000 g/mol molecular weight (MW), 95\% purity and Brookfield LVF viscosity of $260 \mathrm{cP}$ measured in a $1 \%$ aqueous solution at $30 \mathrm{rpm}$, spindle $2 ; 2$ ) a polyanionic cellulose (PAC) with $0.95 \mathrm{DS}, 700,000 \mathrm{~g} / \mathrm{mol} \mathrm{MW}, 98 \%$ purity and Brookfield LVF viscosity of $3,500 \mathrm{cP}$ measured in a $2 \%$ aqueous solution at $30 \mathrm{rpm}$, spindle 3; and 3) partially hydrolyzed polyacrylamide (HPAM) with a $30 \%$ degree of hydrolysis, $20 \times 10^{6} \mathrm{~g} / \mathrm{mol} \mathrm{MW}, 99 \%$ purity and Brookfield LVF viscosity of $3,200 \mathrm{cP}$ measured in a $1 \%$ aqueous solution at $30 \mathrm{rpm}$, spindle 3 .

The Na-bentonite was dispersed in water $(4.86 \% \mathrm{w} / \mathrm{w})$ with different ionic strengths $(\mathrm{S}=0.0,0.015,0.030$ and $0.045 \mathrm{M}) . \mathrm{CaCl}_{2}$ and

*e-mail: luciana@cct.ufcg.edu.br 
$\mathrm{MgCl}_{2}$ were added simultaneously up to $500 \mathrm{~mL}$ of water to obtain different degrees of salinity. The $\mathrm{CaCl}_{2}$ and $\mathrm{MgCl}_{2}$ mixtures contained: $10+10 \mathrm{meq} / 500 \mathrm{~mL}, 20+20 \mathrm{meq} / 500 \mathrm{~mL}$ and $30+30 \mathrm{meq} / 500 \mathrm{~mL}$. The suspensions were stirred rapidly $(17000 \mathrm{rpm})$ for 20 minutes, after which they were treated with different concentrations of polymeric additives. The mixture was then stirred for 5 minutes, allowed to rest for 24 hours, and the apparent and plastic viscosities measured using a Fann model 35A viscometer.

Water loss was measured by using an API filter press under a pressure of $689.5 \mathrm{kPa}$ (100 psi). The water loss was measured after 30 minutes.

\section{Results and Discussion}

Table 1 presents the results of plastic and apparent viscosities for the bentonite suspensions with and without polymer (no salt was added in this experiment). The treatment with polymer changed the plastic and apparent viscosities and water loss. The suspensions treated with $\mathrm{CMC} \mathrm{BV}$ and PAC showed very similar AV values (13.3 and $14.0 \mathrm{cP}$ at $0.6 \mathrm{~g} / \mathrm{L}$, and 15.5 and $15.0 \mathrm{cP}$ at $0.8 \mathrm{~g} / \mathrm{L}$, respectively, although the PV and WL values were very different. The PAC exerted a stronger influence on the reduction of WL while the CMC BV exerted a greater effect on PV, suggesting that these variables are highly dependent on the type of polymer, even if both the polymers derive from cellulose.

The treatment with HPAM (Table 1) significantly increased the $\mathrm{AV}$, which reached values close to $50.0 \mathrm{cP}$, and considerably reduced the WL from 17.7 to $11.4 \mathrm{~mL}$.

Based on these results, it is safe to state that the clay particles and polymer molecules interact, developing structures in different flocculation stages that result from the characteristics of each polymer. CMC BV is a polymer with low viscosity, a very short chain and low molecular weight $(70,000 \mathrm{~g} / \mathrm{mol})$. According to Amorim ${ }^{8}$, polymers with short chains have little effect on the solution's viscosity and their main function is to decrease the WL. Pereira ${ }^{11}$ states that polymers with short chains usually act as deflocculants. This characteristic provides maximum adsorption on clay particle surfaces, coating the particles and increasing the distance between them. PAC is a polymer of high molecular weight $(700,000 \mathrm{~g} / \mathrm{mol})$ and long chains. This polymer has a high DS (0.95) and high solubility, so it becomes more homogenized with clay particles. Its high purity (>98\%) and uniformity in comparison with the substitution of carboxyl groups in the chain prevents the occurrence of flocculation.

The suspension treated with HPAM (Table 1) presented a very different behavior with high AV values, indicating a high degree of flocculation and showing the formation of bridges and encapsulation. This phenomenon occurs more commonly with high molecular weight polymers, which is the case of the HPAM used in this study, which has a molecular weight of 20 million and very long chains.

Table 1. Apparent and plastic viscosities and water loss of bentonite dispersions before and after treatment with polymer, without added salt.

\begin{tabular}{lcccc}
\hline Polymer & Concentration $(\mathrm{g} / \mathrm{L})$ & $\mathrm{AV}(\mathrm{cP})$ & $\mathrm{PV}(\mathrm{cP})$ & $\mathrm{WL}(\mathrm{mL})$ \\
\hline- & - & 12.5 & 4.8 & 17.7 \\
\hline CMC BV & 0.6 & 13.3 & 7.0 & 17.3 \\
& 0.8 & 15.5 & 8.0 & 17.2 \\
\hline PAC & 0.6 & 14.0 & 5.5 & 12.3 \\
& 0.8 & 15.0 & 6.5 & 11.5 \\
\hline \multirow{2}{*}{ HPAM } & 0.6 & 44.5 & 3.0 & 12.6 \\
& 0.8 & 50.5 & 5.5 & 11.4 \\
\hline
\end{tabular}

According to Güngor and Karaoğlan, three possibilities concerning the interaction between polyacrylamide molecules and clay particles must be considered: i) an anionic exchange between the hydroxyl groups on the mineral surface and the polymer's carboxyl anions; ii) the formation of hydrogen bonds between the hydroxyls on the particle surfaces and the polymer's $\mathrm{C}=\mathrm{O}$; iii) the establishment of bridges involving divalent ions originating from electrostatic forces.

Figure 1 shows a plot of the apparent viscosity of bentonite suspensions treated with polymer as a function of ionic strength $(\mathrm{S})$. The apparent viscosity of bentonite suspensions treated with different concentrations of CMC BV showed almost no change with increased $S$, i.e., the salinity of the bulk produced practically no effect on the behavior of the CMC BV. With regard to the PAC, the apparent viscosity was almost constant at low ionic strengths of $S=0.0$ and $\mathrm{S}=0.015 \mathrm{M}$, but increased rapidly at $\mathrm{S}=0.030$ and $\mathrm{S}=0.045 \mathrm{M}$. In the case of HPAM, there was an initial increase in the apparent viscosity at $S=0.015 \mathrm{M}$, followed by a decrease as the ionic strength increased. This finding indicates that each type of polymer presents a distinct behavior in systems with different ionic strengths. Among the polymers studied here, the $\mathrm{CMC} \mathrm{BV}$ presented the greatest resistance to different degrees of salinity.

Figure 2 plots the plastic viscosity of the bentonite suspensions treated with polymer as a function of ionic strength. As can be seen, the plastic viscosity of the suspensions treated with CMC BV remained almost constant as $\mathrm{S}$ increased from 0.015 to $0.030 \mathrm{M}$. At $\mathrm{S}$ of more than $0.030 \mathrm{M}$, the plastic viscosity decreased, indicating that high concentrations of salt affect the polymer's hydration and its interaction with clay particles. High values of plastic viscosities were obtained with a polymer concentration of $0.8 \mathrm{~g} / \mathrm{L}$ and with the same ionic strength.

The behavior of apparent and plastic viscosities presented by the bentonite dispersions treated with CMC BV showed that polymer molecules are absorbed in clay particles even in a saline system. However, at a high ionic strength $(\mathrm{S}=0.045 \mathrm{M})$, this adsorption is limited by the high concentration of calcium and magnesium ions. These cations inhibit the "swelling" of the clay particles and cause agglomeration. Also, the polymer chain does not unravel and curl up into a "yarn ball" shape.

In bentonite suspensions treated with PAC and HPAM, significant changes occurred in the plastic viscosity values with the increased $S$,

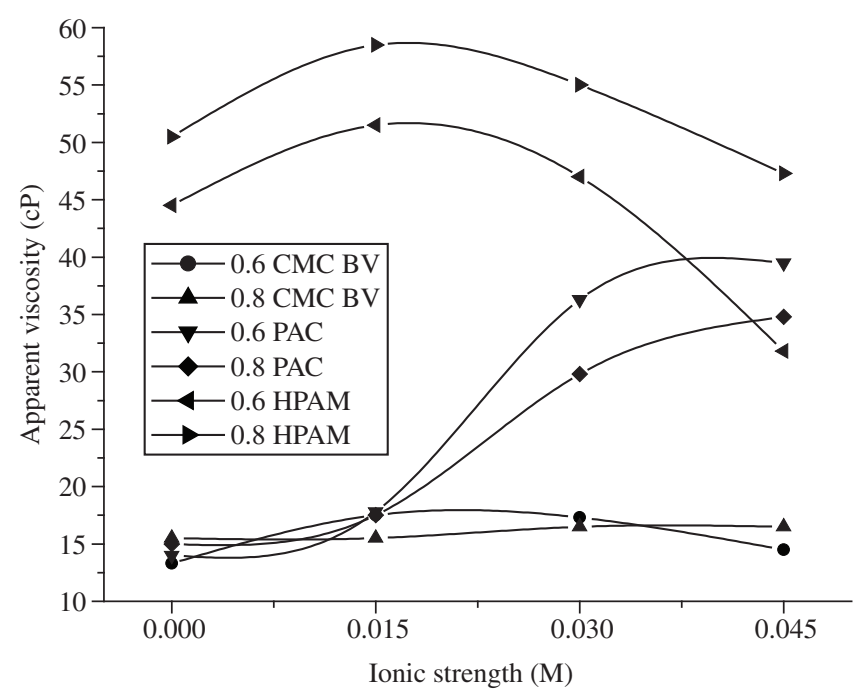

Figure 1. Influence of ionic strength on the apparent viscosity of bentonite suspensions treated with polymer. 


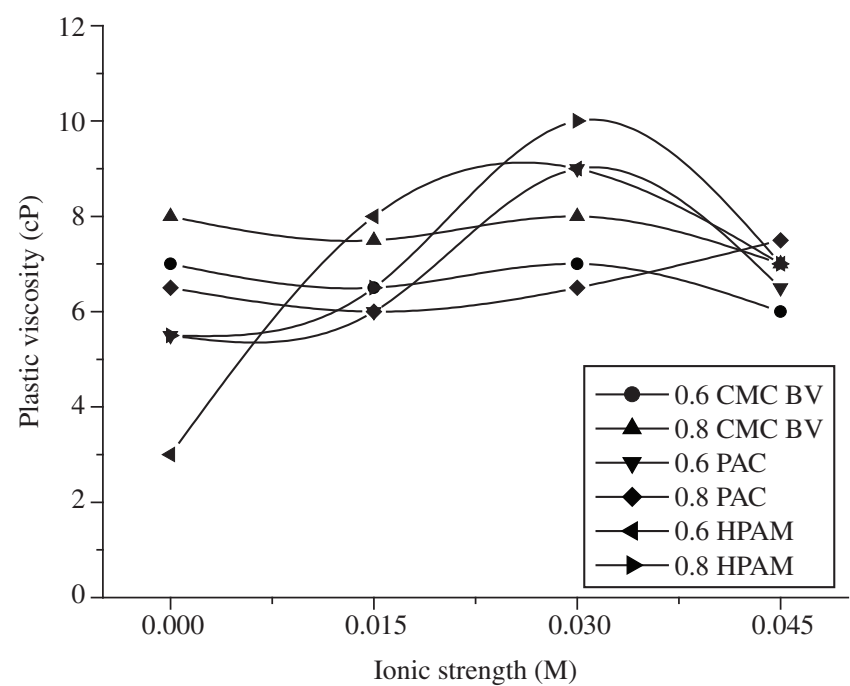

Figure 2. Influence of ionic strength on the plastic viscosity of bentonite suspensions treated with polymer.

mainly at $0.6 \mathrm{~g} / \mathrm{L}$ of polymer; the increase in ionic strength caused the plastic viscosity to increase up to $\mathrm{S}=0.030 \mathrm{M}$, followed by a decrease in the plastic viscosity. At a concentration of $0.8 \mathrm{~g} / \mathrm{L}$ of PAC, the plastic viscosity increased along with increased $\mathrm{S}$.

The increase in the apparent viscosity for PAC at a high ionic strength, unlike CMC BV, was due to the long length of the molecules and the presence of high concentrations of $\mathrm{Ca}^{2+}$ and $\mathrm{Mg}^{2+}$ ions, which promoted the formation of large "yarn balls", increasing the apparent viscosity.

With the increase in PAC concentration, the effect of the ionic strength was minimized by higher polymer concentrations.

As mentioned earlier herein, the plastic and apparent viscosities of the clay suspensions treated with polymer were influenced by the ionic strength, and the CMC BV polymer showed the best behavior, since its viscosity remained unchanged in salt mediums of different ionic strengths.

Figure 3 illustrates the water loss of the bentonite suspensions treated with polymer as a function of ionic strength. Note that, with the exception of HPAM, the suspensions treated with different polymers and ionic strengths showed no significant changes in water loss. For HPAM, the formation of "yarn balls" with their long chains in the presence of high ionic strengths decreased the surface area available for hydration, resulting in large amounts of "free water". This effect was minimized when the concentration of polymer increased with the increase in ionic strength.

According to Hughes et al. ${ }^{3}$, the increase in salinity of clay suspensions without polymer can cause flocculation of bentonite particles and result in an increase double that of the water loss. Therefore, the results presented in Figure 3 indicate that, for CMC $\mathrm{BV}$ and PAC with a concentration of $0.8 \mathrm{~g} / \mathrm{L}$, the dispersions were more resistant to changes in water loss with high salinity than was HPAM. CMC BV and HPAM polymers prevent the flocculation of bentonite particles.

According to Hughes et al. ${ }^{3}$, the water loss of bentonite suspensions treated with polymer depends on the polymer concentration, particularly in the case of cellulose polymer such as CMC and PAC, with a molecular weight close to $50,000 \mathrm{~g} / \mathrm{mol}$, and this variable decreases as the ionic strength increases.

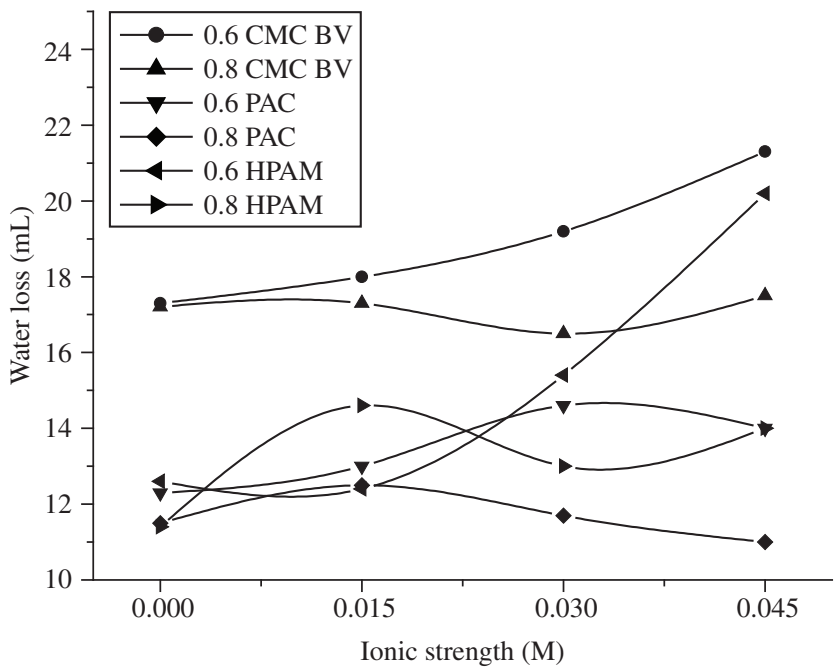

Figure 3. Influence of ionic strength on the water loss of bentonite suspensions treated with polymer.

\section{Conclusions}

Our evaluation of the influence of ionic strength on the plastic and apparent viscosities and water loss of sodium bentonite suspensions treated with polymer led us to the following conclusions:

i) The polymeric treatment can change the viscosities and water loss of bentonite suspensions, leading to the development of structures with different degrees of flocculation. HPAM acts as a flocculant and CMC BV and PAC as deflocculants;

ii) The apparent and plastic viscosities and water loss of bentonite suspensions treated with CMC BV are only slightly affected by increases in salinity. On the other hand, suspensions treated with PAC and HPAM are strongly affected by the suspension's salinity, according to the concentration of the polymer; and

iii) Among the polymers studied here, CMC BV presented the highest resistance to changes in rheological properties with the increase of the suspensions' salinity.

In summary, it can be concluded that the presence of salt and the increase of salinity in these suspensions strongly affect the plastic and apparent viscosities and water loss of dispersions treated with polymers, and this influence is even stronger when the suspensions are treated with PAC and HPAM.

\section{Acknowledgments}

The authors gratefully acknowledge CNPq (Brazil) for a DCR scholarship (Process No. 309873/2003-7), System Mud Industria e Comercio Ltda for supplying the polymeric additives, and LABDES for the use of its laboratory facilities.

\section{References}

1. Güngör N, Ece ÖI. Effect of the adsorption of non-ionic polymer poly(vinyl)pyrolidone on the rheological properties of $\mathrm{Na}$-activated bentonite. Materials Letters. 1999; 39:1-5.

2. Güngör N, Karaoğlan S. Interaction of polyacrylamide polymer with bentonite in aqueous systems. Materials Letters. 2001; 48:168-175.

3. Hughes TL, Jones TGJ, Houwen OH. Chemical characterization of CMC and its relationship to drilling-mud rheology and fluid loss. SPE Drilling and Completion; 1993. p. 157-164. 
4. Alemdar A, Atici O, Güngör N. The influence of cationic surfactants on rheological properties of bentonite-water systems. Materials Letters. 2000; 43:57-61.

5. Güngör N, Alemdar A, Atici O, Ece Ö I. The effect of SDS surfactant on the flow and zeta potential of bentonite suspensios. Materials Letters. 2001; 51:250-254.

6. Yalçin T, Alemdar A, Ece Ö I, Güngör N, Çoban F. By particle interactions and rheological properties of bentonites + ALS suspensios. Materials Letters. 2002; 53:211-215.

7. Esmer K, Güngör N. The effect of $\mathrm{NaCl}$ electrolyte on rheological properties of the different clay types. Applied Mechanics and Engineering. 1999; 4:203-206.
8. Amorim LV. Melhoria, proteção e recuperação de fluidos hidroargilosos para uso na perfuração de poços de petróleo. [Unpublished D. Phil thesis]. Campina Grande: Federal University of Campina Grande; 2003.

9. Oliveira IR, Studart AR, Pileggi RG, Pandolfelli VC. Dispersão e Empacotamento de Partículas, São Paulo: Fazendo Arte Editorial; 2000.

10. Somasundaran P, Healy TW, Fuerstenau DW. The aggregation oh colloidal alumina dispersion by adsorbed surfactant ions. Journal of Colloid and Interface Science. 1996; 22(1):599-605.

11. Pereira E. Química dos Polímeros e Aplicações - Parte III. [homepage on the Internet]. Itajaí - SC: System Mud Indústria e Comércio Ltda. Available from: http://www.systemmud.com.br/index.php?pg=literatur a\&sub=literatura_home\&artigo=lit_003. 